\title{
Transforming the relationship between staff and students to effect change
}

\author{
Iman Hassan, Sarah Hayes \\ Aston University
}

\section{Transforming the relationship between staff and students to effect change}

Higher education institutions commonly involve students in course evaluations and staffstudent committees, thereby eliciting a 'student voice' with the aim of raising awareness of student experiences of teaching and learning at university. More recently, emphasis has been placed not merely on consulting students, but rather on treating them as legitimate equals in a student-staff partnership whose parties jointly make decisions relating to the design of teaching approaches, courses and curricula (Healey, Flint and Harrington, 2014). This opinion piece argues that a transformed and truly collaborative staff-student partnership is both necessary and valuable in making decisions about how technology, an often neglected aspect of curriculum design processes, may be effectively embedded to enhance student learning experiences.

In recent decades, as ever-greater value has been placed nationally on Higher Education's contribution to the global economy, there has been a concomitant prioritising of what may serve to meet the needs of industry and provide competitive advantage. Students as a consequence recognise the role of a degree in securing future material affluence, though may be less aware of study as a continuing investment in the self (Molesworth, Nixon and Scullion, 2009). Students are primarily consumers in this model and thus may not, in their view of their own development, appreciate the transformative potential that university education offers. There is a compelling case, therefore, for institutions to go beyond merely listening to 'student voice', a term which tends to perpetuate the notion of students as consumers and imposes a singular identity on this diverse body of individuals; instead, engaging students as partners and co-producers stimulates deeper, more probing and reflective questions and supports diversity.

Indeed, there is an increasing body of literature highlighting the benefits of student-staff partnerships in promoting active engagement and mutual learning between students and staff (Little, 2011). Such a two-way transmission favours contributions made by students that challenge the lack of agency students typically have within university educational structures and processes, endorsing change that is more meaningful and fruitful. Whilst technologyrelated partnerships have only recently been implemented, projects involving students as partners in the development of online education and support resources have already demonstrated such positive outcomes as the positive general reception of those resources by student cohorts and serious critical scrutiny of practice by a greater number of staff (Higher Education Academy, 2015).

Notably, an important role for students is to teach staff about the meaning of new technologies within their personal learning environments, with this information shaping how staff use technological and online resources tailored to students' needs. The cultivation of an open and continuing dialogue would help to change staff assumptions about students, challenge the thinking of staff and provoke them to look at technological applications from a student point of view. Students are accustomed to the learning environment and do offer a fresh perspective that may provide practical solutions to issues that staff may not necessarily 
have considered. Such principles were incorporated by Iman Hassan and Nikolay Boychev into a taught day for staff at Aston University on July 15th 2015 and had a clear impact on staff approaches to designing technology into their PG Dip assessment modules, presented in November 2015. Instead of simply treating students as a 'voice', these lecturers sought roles for their students in their proposed projects, whether as partners in the design of $e$ portfolios, or within flipped classrooms, or as peer mentors via virtual classrooms or in terms of dissemination.

A partnership approach has the potential to identify uses of technology that revolutionise learning experiences. For example, redesigning modules to provide active learning opportunities for students can represent a significant advance from common practices in which technology simply replicates or supplements traditional activities (Kirkwood and Price, 2014). Whilst technology is often used to distribute lecture slides, handouts and recordings with operational and sometimes quantitative improvements - for instance, in providing greater flexibility for students and consequently increasing the time spent engaged on tasks respectively (Kirkwood and Price, 2014) - the capability of technology to improve learning experiences can go so much further than this.

More specifically, when used in innovative and creative ways, technology can help develop deeper learning, higher-order thinking skills and critical awareness, as observed in the implementations of, to list a few examples, problem-based blended learning, video games aiming to improve numerical skills and the use of blogs to encourage self-reflection (Kirkwood \& Price, 2014). Importantly, skills developed can encourage students to 'transform themselves from objects to subjects, from passive to active' (Kellner, 1998) and 'become critical producers of meanings and texts, able to resist manipulation and domination' (Kellner, 1998), preparing them to think and act critically beyond university.

Many student-staff partnerships have been conducted to target elements of courses and curricula, but there is a pressing need to include designing in technology. This becomes increasingly relevant at a time when new technologies continue to alter every aspect of our society and culture.

\section{Reference list}

Healey, M., Flint, A., and Harrington, K. (2014) Engagement through partnership: students as partners in learning and teaching in higher education. York: Higher Education Academy.

Higher Education Academy (2015) Digital Literacies in the Disciplines (DLinD). Available at: https://www.heacademy.ac.uk/workstreams-research/themes/online-learning/online-learningprojects/digital-literacies-disciplines (Accessed: 4 November 2015).

Kellner, D. (1998) 'Multiple literacies and critical pedagogy in a multicultural society.' Educational Theory, 48(1), 103-122.

Kirkwood, A. and Price, L. (2014) 'Technology-enhanced learning and teaching in higher education: what is 'enhanced' and how do we know? A critical literature review.' Learning, Media and Technology, 39(1), 6-36.

Little, S. (ed.) (2011) Staff-student partnerships in higher education. London: Continuum. 


\section{Opinions}

Molesworth, M., Nixon, E. and Scullion, R. (2009) 'Having, being and higher education: the marketisation of the university and the transformation of the student into consumer.'

Teaching in Higher Education, 14(3), 277-287. 